\title{
Combustion Phasing Model for Control of a Gasoline-Ethanol Fueled SI Engine with Variable Valve Timing
}

\author{
Carrie M. Hall ${ }^{a *}$, Gregory M. Shaver ${ }^{a}$, Jonathan Chauvin $^{b}$ and Nicolas Petit ${ }^{c}$ \\ ${ }^{a}$ Ray W. Herrick Laboratories, School of Mechanical Engineering, Purdue University, West Lafayette, IN 47907, USA \\ ${ }^{b}$ IFP Energies Nouvelles, Rueil-Malmaison, France \\ ${ }^{c}$ Centre Automatique et Systèmes, École des Mines de Paris, Paris, France
}

\begin{abstract}
Concern over the availability of fossil fuels and energy usage have produced an interest in both alternative fuels and new engine technologies such as variable valve timing to improve engine efficiency. Fuel-flexible engines permit the increased use of ethanol-gasoline blends. Ethanol is a renewable fuel which has the added advantage of improving performance in typically knock-limited operating regions due to the higher octane rating of the fuel. Furthermore, many modern engines are also being equipped with variable valve timing (VVT), a technology which allows increased control of the quantity of burned gas in-cylinder and can increase engine efficiency by reducing the need for throttling. The burned gas fraction as well as the blend ratio of ethanol impact the combustion timing and capturing these effects is essential if the combustion phasing is to be properly controlled.

Combustion efficiency is typically tied to an optimal CA50 (crankangle when $50 \%$ of fuel is burned) for an engine. This paper proposes a physically-based model which captures combustion phasing and is designed to provide accurate estimates of CA50 for real-time control efforts allowing the CA50 to be adjusted to its optimal value despite changes in fuel and valve overlap. This control-oriented model was extensively validated at over 500 points across the engine operating range for four blends of gasoline and ethanol.
\end{abstract}

\section{INTRODUCTION}

Fuel-flexible SI engines incorporating variable valve timing enable the efficient utilization of a nearly $\mathrm{CO}_{2}$ neutral, domestically available renewable fuel. While ethanol is an attractive option for offsetting dependence on petroleum based gasoline, the differences in fuel properties between gasoline and ethanol (as summarized in Table I) can significantly alter engine performance [8], [24], [7]. Due to the different molecular structure of ethanol, the stoichiometric air-fuel ratio of ethanol is substantially different than gasoline and the air and fuel controllers must target different values for ethanol blends. Ethanol also has a different laminar flame speed than gasoline; therefore, the rate at which flames propagate during combustion will differ depending on the fuel ethanol content and combustion phasing will be directly affected. In addition, as a result of its higher octane rating, ethanol has a higher resistance to knock than gasoline. While the optimal CA50 timing is typically $7-8^{\circ} \mathrm{CA}$ after top dead

\footnotetext{
* Corresponding Author. Email address: hallcm@purdue.edu
}

center (TDC) [12], at higher speed/load combinations, spark timing must be retarded when running with gasoline in order to avoid knock. When spark advance is retarded and CA50 no longer occurs at its optimal instant, efficiency is sacrificed. Since ethanol's knock-limited operating region is relatively small [24], [23], such efficiency sacrifices are not required.

TABLE I

FUEL PROPERTIES.

\begin{tabular}{|c|c|c|}
\hline Property & Gasoline & Ethanol \\
\hline Molecular formula & $C_{6.16} H_{11.52}$ & $C_{2} H_{6} O$ \\
\hline Density $\left(\mathrm{kg} / \mathrm{m}^{3}\right)$ & 744 & 790 \\
\hline Lower heating value $(\mathrm{MJ} / \mathrm{kg})$ & 44.1 & 26.9 \\
\hline Octane number & 98 & 129 \\
\hline
\end{tabular}

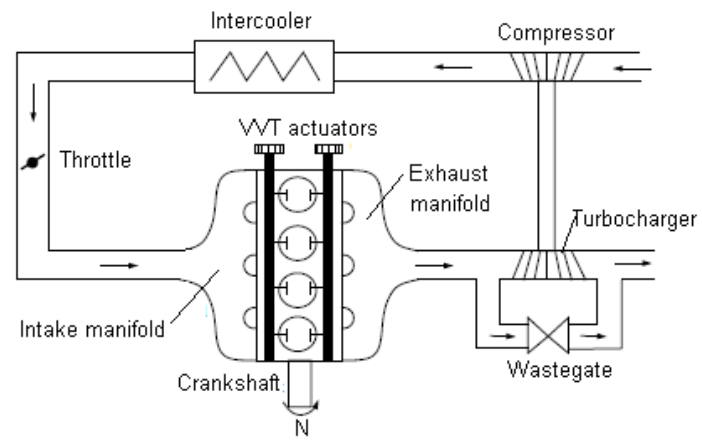

Fig. 1. Diagram of SI Engine with VVT and Turbocharger.

The air and fuel controllers of a SI engine, such as that pictured in Figure 1, keep the air-to-fuel ratio (AFR) at a desired value (typically the stoichiometric AFR). In order to maintain the desired AFR, throttling is required at part-load; however, throttling causes significant decreases in engine efficiency. Engines with variable valve timing can avoid some of these throttling losses [28], [14], [10]. In a study by [10], the authors found that control of VVT could provide a $6 \%$ reduction in fuel consumption and in a theoretical study [29], it was demonstrated that VVT had the potential to lower fuel consumption by up to $13 \%$. To achieve these reductions, instead of throttling to reduce the volume of incoming fresh air, some of the fresh air is displaced by increasing the mass of in-cylinder combustion products through the use 
of valve overlap. When there is no overlap (Figure 2), the burned gases present in the cylinder are residual exhaust gas; however, when overlap occurs (Figure 2), exhaust gases can enter the intake manifold displacing some of the fresh air. However, the addition of burned gases serves to slow flame propagation and directly impacts the rate at which fuel burns.

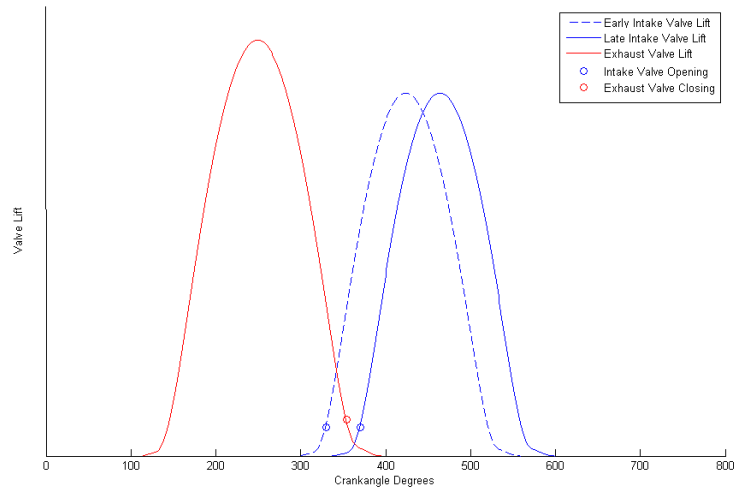

Fig. 2. Intake and exhaust valve lifts with varying valve overlaps.

Due to the impact of gasoline-ethanol blend ratio and burned gas fraction on combustion timing, adaptation in ignition control is required. A conventional ignition controller uses static look-up tables to dictate spark timings which allows an optimal rate of fuel burn to be achieved. In steady state, these look-up tables provide a spark timing which ensures that the middle of combustion (CA50- crankshaft angle when $50 \%$ of the fuel has burned) occurs at its optimal timing. However, if the same look-up tables for ignition control are used for gasoline, ethanol, and gasoline-ethanol blends, engine performance will be suboptimal when running any blend fraction of ethanol [8].

A physically-based, control-oriented model which accurately estimates the CA50 for various fuel blends and burned gas fractions could be used to synthesize either feedback or feedforward control algorithms. This work focuses on the development of such a model which is capable of providing cylinder-specific, cycle-to-cycle estimates of CA50 during engine operation. While a number of models have been created which capture combustion phasing for conventional SI engines [31], [30], [17], [5], [27], [18], [19], only the models presented by [18] and [19] included positive valve overlap effects and only that by [5] included ethanol blends.

On the other hand, the control-oriented model detailed in this paper captures the impact of both ethanol blend ratio and VVT-enabled burned gas variation and is based on the general physical relationships which govern the gas exchange, compression and flame propagation processes. The details of this model are given and the model is validated for 4 different fuel blends at over 500 operating points including a wide variety of speed/load conditions over the engine operating range of the engine as well as variation in spark timing and valve overlap.

\section{Combustion Phasing Model}

Since the model is designed to be used for control of combustion phasing, it is desirable to capture the underlying dynamics of the system in a manner which is representative but can be used for real-time estimation and control of CA50 on a fuel-flexible engine with variable valve timing. While an in-cylinder pressure measurement could be used with the model for control, this model is not dependent on such a pressure measurement and uses only available on-engine sensor measurements to provide accurate estimates of the timing of combustion phasing. The sensor measurements which are commonly available and are utilized in this model are the following: 1) engine speed (N), 2) spark ignition timing (SIT), 3) injected fuel mass $\left.\left(M_{\text {fuel }}\right), 4\right)$ intake manifold pressure $\left.\left(P_{I M}\right), 5\right)$ intake manifold temperature $\left.\left(T_{I M}\right), 6\right)$ exhaust manifold pressure $\left(P_{E M}\right)$, and 7) exhaust manifold temperature $\left(T_{E M}\right)$.

On engines with variable valve timing, the commanded valve opening and closing timings will also be used. In addition, to capture the effects of ethanol content on the combustion phasing, the ethanol blend fraction of the fuel must also be either measured or estimated. A number of studies have developed methods of ethanol blend fraction estimation including [1], [2], [3], [8], [25] and [33]. Such an estimation technique can be used to supply an estimate of the ethanol content to the combustion phasing model.

In order to compute CA50, the model is comprised of three phases: gas exchange, compression, and flame propagation, as shown in Figure 3. The dynamics of these processes are captured by physically based equations as described in the following sections.

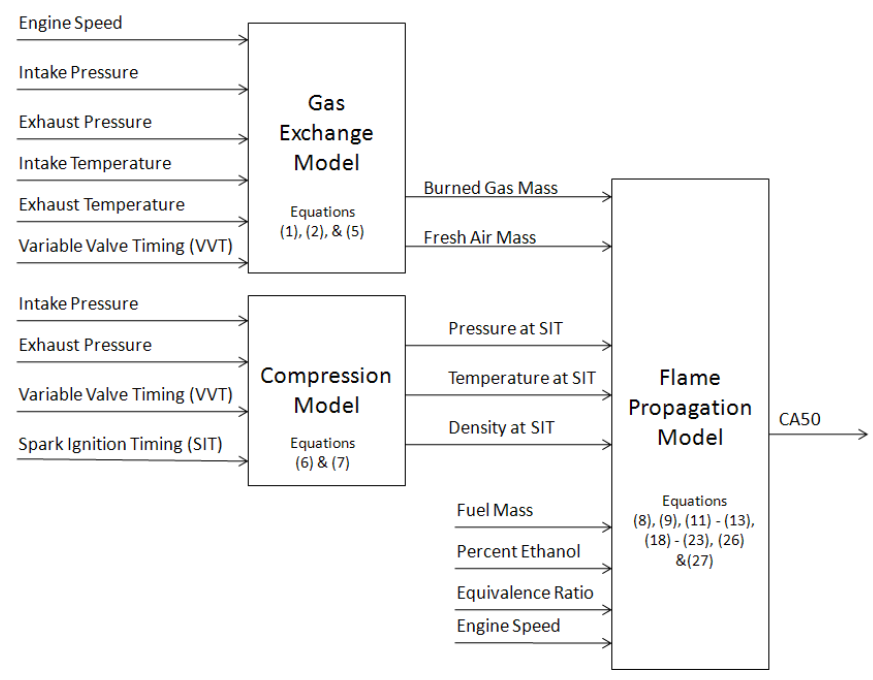

Fig. 3. Model diagram.

The notation used in this model is summarized in the appendix.

\section{A. Model Assumptions}

In this model, it is assumed that the in-cylinder mixture is homogenous. After combustion begins, fuel is burned in a thin reaction zone which separates the burned and unburned regions in the cylinder. A pressure equilibrium is assumed between the burned and unburned regions. 


\section{B. Gas Exchange Modeling}

In order to capture the dynamics of combustion phasing, it is crucial to have an accurate estimate or measurement of the contents of the cylinder at intake valve closing (IVC). The mixture in the cylinder will be made up of fresh air, residual and reinducted exhaust gases, and fuel. The mass of fuel entering into the cylinder is controlled by the existing engine fueling control and thus, is known. However, the mass of fresh and burned gases in the cylinder must be calculated from appropriate physically-based models. The fuel-flexible engine considered in this work is also equipped with variable valve timing (VVT). With a VVT system, it is possible to alter the intake and exhaust valve opening and closing such that both the intake and exhaust valves are open for a period of time. This valve overlap can significantly influence the amount of fresh air and burned gases present in the enginecylinder at IVC.

1) Fresh Air Mass: In order to calculate the mass of fresh air, a previously developed and validated cylinder filling model [20] for an engine with VVT is used. This model estimates fresh air flow as

$$
M_{\text {fresh }}=\alpha_{1} \frac{P_{I M} \cdot V_{I V C}}{R \cdot T_{I M}}-\alpha_{2} \frac{O F}{N}
$$

where $O F$ is an overlap factor, $N$ is the engine speed, $\alpha_{1}$ is a function of engine speed and intake manifold pressure and represents the volumetric efficiency and $\alpha_{2}$ is also a function of engine speed and intake manifold pressure and may be positive or negative depending on whether exhaust mass is flowing into the cylinder (backflow) or fresh air is being driven out the exhaust (scavenging). The first term on the right hand side of Equation 1 represents the total mass in cylinder at IVC and the second term represents the aspirated mass from the exhaust.

2) Burned Gas Mass: The burned gases present in the cylinder are composed of residual exhaust gas as well as possible backflow from the exhaust manifold. In cases where there is negative valve overlap (NVO), exhaust valve closing (EVC) occurs before intake valve opening (IVO) as shown in Figure 2 and the total mass of burned gas is only due to residual exhaust gas which is trapped in the cylinder at EVC. The mass of burned gas can therefore be found by applying the ideal gas law as shown in Equation 2 with the assumption that the pressure and temperature in the cylinder at EVC are the same as the conditions in the exhaust manifold.

$$
M_{b g, N V O}=\frac{V_{E V C} \cdot P_{E M}}{R \cdot T_{E M}}
$$

When IVO occurs prior to EVC (Figure 2), residual gases as well as backflow and scavenging must be considered. In cases with positive valve overlap (PVO), the residual gas mass can be calculated using the ideal gas law as

$$
M_{r e s}=\frac{V_{I V O} \cdot P_{E M}}{R \cdot T_{E M}}
$$

In the period of time between IVO and EVC, gases can flow between the intake manifold, the engine cylinder, and the exhaust manifold. Any residual exhaust gas which is expelled into intake manifold will be reinducted during the intake stroke. In addition, depending on the placement of IVO and EVC and the pressure differential across the engine, residual gas may flow into the exhaust manifold or exhaust gas from the exhaust manifold may re-enter the cylinder (this is commonly referred to as backflow). The portion of residual gas which is lost to the intake and exhaust manifolds during this time of valve overlap can be found by the ideal gas law. The fraction of this residual mass which exits the exhaust manifold is assumed to be proportional to the pressures in the intake and exhaust manifolds. Thus, in a similar method as that used by [16], these backflow effects are captured by

$$
M_{\text {backflow }}=\frac{P_{I M}}{P_{I M}+P_{E M}} \cdot \frac{\left(V_{E V C}-V_{I V O}\right) \cdot P_{E M}}{R \cdot T_{E M}}
$$

By combining Equations 3 and 4, the total burned gas mass in the case of PVO is

$$
M_{b g, P V O}=\frac{V_{I V O} \cdot P_{E M}}{R \cdot T_{E M}}+\frac{P_{I M}}{P_{I M}+P_{E M}} \cdot \frac{\left(V_{E V C}-V_{I V O}\right) \cdot P_{E M}}{R \cdot T_{E M}}
$$

Equations 1, 2, 5 and the controlled fueling mass provide the composition of the cylinder mixture at intake valve closing (IVC).

\section{Compression Modeling}

After the contents of the cylinder (i.e. the burned gas mass and fresh air mass) are computed, the evolution of the temperature and pressure of these contents from IVC to spark ignition timing (SIT) must be computed. In this phase, polytropic compression with a polytropic coefficient $(n)$ of 1.29 is assumed. Furthermore, the temperature and pressure at IVC are assumed to be approximately equal to those in the intake manifold (IM). The conditions at SIT can be found by Equations 6 and 7 .

$$
\begin{gathered}
P_{S I T}=P_{I M} \cdot\left(\frac{V_{I V C}}{V_{S I T}}\right)^{n} \\
T_{S I T}=T_{I V C} \cdot\left(\frac{V_{I V C}}{V_{S I T}}\right)^{n-1}
\end{gathered}
$$

In order to take into account the effect of burned gases on the initial temperature at IVC, The temperature at IVC, $T_{I V C}$, is given by

$$
T_{I V C}=Y_{b g} \cdot T_{E M}+\left(1-Y_{b g}\right) \cdot T_{I M}
$$

where $Y_{b g}$ is the burned gas fraction in-cylinder.

\section{Flame Propagation Modeling}

Shortly after a spark is applied, the mixture will begin to burn. In order to estimate the time it takes for the fuel to burn, it is necessary to predict the manner in which the flame propagates. 
1) Inputs: In addition to the pressure and temperature at SIT determined by Equations 6 and 7 in the compression phase of the model, it is also necessary to know the mass fraction of fuel in the cylinder and the initial density of the cylinder contents at SIT. Since the in-cylinder contents are assumed to be homogenous, mass fraction of fuel in the unburned zone is

$$
Y_{f u e l, u}=\frac{M_{\text {fuel }}}{M_{\text {fuel }}+M_{\text {fresh }}+M_{b g}}
$$

The initial density at SIT is

$$
\rho_{u, S I T}=\frac{M_{f u e l}+M_{f r e s h}+M_{b g}}{V_{S I T}}
$$

Equations 6-10 provide the conditions at SIT which are the initial inputs to the flame propagation model.

2) Mass Fraction of Fuel Burned: Following spark ignition, the rate at which fuel is burned can be described by

$$
\frac{d m_{\text {fuel }}}{d t}=\rho_{u} \cdot U_{\text {turb }} \cdot \bar{A}
$$

where $\rho_{u}$ is the density in the unburned region, $U_{\text {turb }}$ is the turbulent flame speed, and $\bar{A}$ is the mean flame surface area [34].

Alternatively, the following relationship for the fraction of fuel burned $\left(x_{f u e l}\right)$ can be derived from Equation 11.

$$
\frac{d x_{\text {fuel }}}{d t}=\frac{1}{M_{\text {fuel }}} Y_{\text {fuel }, u} \cdot \rho_{u} \cdot U_{\text {turb }} \cdot \bar{A}
$$

The total mass of fuel injected $\left(M_{f u e l}\right)$ is known and the mass fraction of fuel (Equation 9) throughout the unburned zone is considered uniform due to the homogeneity assumption. In order to evaluate Equation $12, \rho_{u}, U_{\text {turb }}$, and $\bar{A}$ must also be determined.

3) Unburned Density and Temperature: In order to calculate the evolution of the temperature and density in the unburned zone, a polytropic relationship is assumed [12] as captured by Equations 13 and 14 .

$$
\begin{gathered}
T_{u}=T_{u, S I T} \cdot\left(\frac{P}{P_{S I T}}\right)^{\frac{n-1}{n}} \\
\rho_{u}=\rho_{u, S I T} \cdot\left(\frac{P}{P_{S I T}}\right)^{\frac{1}{n}}
\end{gathered}
$$

4) In-cylinder Pressure: The change in pressure in the flame propagation stage can be deduced from the First Law of Thermodynamics for a closed system

$$
\frac{d U}{d t}=\frac{d Q}{d t}-P \frac{d V}{d t}
$$

The heat addition due to combustion of the fuel can be expressed as

$$
\frac{d Q}{d t}=M_{f u e l} \cdot Q_{L H V} \cdot \frac{d x_{f}}{d t}
$$

in which $Q_{L H V}$ is the lower heating value of the fuel used. Assuming constant specific heats and an ideal gas and plugging in Equation 16 into Equation 15, yields

$$
(\gamma-1) \cdot M_{\text {fuel }} \cdot Q_{L H V} \cdot \frac{d x_{\text {fuel }}}{d t}=\gamma \cdot P \frac{d V}{d t}+V \frac{d P}{d t}
$$

which is used to evaluate the evolution of in-cylinder pressure following SIT.

5) Mean Flame Surface: The mean flame surface is modeled [17] as a sphere at the beginning of combustion as

where

$$
\begin{gathered}
\bar{A}=4 \cdot \pi \cdot\left(r_{\text {flame }}\right)^{2} \\
r_{\text {flame }}=\sqrt[3]{\frac{3 \cdot V_{b}}{4 \cdot \pi}}
\end{gathered}
$$

in which $V_{b}$ is the burned volume given by Equation 20 .

$$
V_{b}=V-V_{u}=V-\frac{1-x_{\text {fuel }}}{\rho_{u}} \cdot\left(M_{f u e l}+M_{\text {fresh }}+M_{b g}\right)
$$

Figure 4 demonstrates the mean flame surface model used.

After the flame reaches the piston head, the flame progressively becomes a cylinder and the flame area is calculated by Equations 21 and 22, in which the distance between the cylinder head and the piston is $\delta l$.

$$
\begin{gathered}
\bar{A}=2 \cdot \pi \cdot\left(r_{\text {flame }}\right) \cdot \delta l \\
r_{\text {flame }}=\sqrt{\frac{V_{b}}{\pi \cdot \delta l}}
\end{gathered}
$$

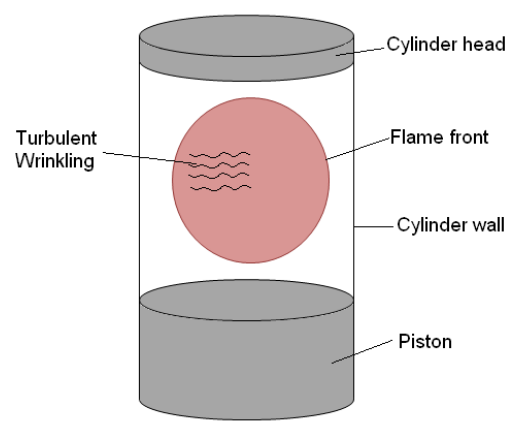

Fig. 4. Mean flame surface area model.

6) Turbulent Flame Speed: The turbulent flame speed, $U_{t u r b}$, has been shown to be proportional to the intensity of turbulence in-cylinder and the laminar flame speed. While the turbulence intensity is impacted by a number of factors, it is largely a function of mean piston speed [26]. Thus, one method of capturing the turbulent flame speed is

$$
U_{\text {turb }}=f \cdot U_{L}
$$

in which $f$ is a turbulence-enhancement factor which is proportional to engine speed and $U_{L}$ is the laminar flame speed [13], [15], [26]. The laminar flame speed is given by

$$
\begin{gathered}
U_{L}=U_{L, 0}\left(\frac{T_{u}}{T_{a m b}}\right)^{\alpha}\left(\frac{P}{P_{a m b}}\right)^{\beta}\left(1-2.06 \cdot Y_{b g}^{0.75}\right) \\
U_{L, 0}=Z \cdot W \cdot \phi^{\eta} \cdot e^{-\xi \cdot(\phi-1.075)^{2}}
\end{gathered}
$$


in which $Z$ is fuel dependent and $W, \eta, \xi, \alpha$, and $\beta$ are fuel independent. The mass fraction of burned gases is $Y_{b g}$. This relationship was developed by [6], [11], [22], [4], [32], [21]. The values for $Z, W, \eta, \xi, \alpha$, and $\beta$ are given in Table II in which $X_{E}$ is the mole fraction of ethanol in the fuel. These constants are in close agreement with studies by Syed [32], Byraktar [6] and Lindström [21].

TABLE II

VALUES FOR CONSTANTS IN LAMINAR FLAME SPEED.

\begin{tabular}{|c|c|}
\hline $\mathrm{Z}$ & $1+0.07 X_{E}^{0.35}$ \\
\hline $\mathrm{W}$ & 0.4658 \\
\hline$\eta$ & 0.3 \\
\hline$\xi$ & 4.48 \\
\hline$\alpha$ & 0.9 \\
\hline$\beta$ & -0.05 \\
\hline
\end{tabular}

The turbulent flame speed is then calculated by

$U_{t u r b}=(a \cdot N+b) \cdot U_{L, 0}\left(\frac{T_{u}}{T_{a m b}}\right)^{\alpha}\left(\frac{P}{P_{a m b}}\right)^{\beta}\left(1-2.06 \cdot Y_{b g}^{0.75}\right)$

where $\mathrm{a}$ and $\mathrm{b}$ are constants of 0.0025 and 3.4 respectively.

This flame propagation model is physically based and generalizable to different engine architectures. It also takes into account the ethanol blend fraction of the fuel. The complexity of the model is kept to a minimum in order to allow the model to be used for control purposes. The entire flame propagation model is captured by the following two state model obtained by combining Equations 12, 13, 14, 17, $18-22,25$, and 26.

$$
\begin{gathered}
\frac{d x_{f u e l}}{d t}=\frac{1}{M_{f u e l}} Y_{f u e l, u} \cdot \rho_{u, S I T} \cdot\left(\frac{T_{u, S I T}}{T_{a m b}}\right)^{\alpha} \\
\left(\frac{P^{(1+(n-1) \cdot \alpha) / n+\beta}}{P_{S I T}^{(1+(n-1) \cdot \alpha) / n} \cdot P_{a m b}^{\beta}}\right) \cdot(a \cdot N+b) \cdot U_{L, 0} \cdot\left(1-2.06 \cdot Y_{b g}^{0.75}\right) \cdot \bar{A}
\end{gathered}
$$

$$
\frac{d P}{d t}=\frac{\gamma-1}{V} \cdot M_{f u e l} \cdot Q_{L H V} \cdot \frac{d x_{f u e l}}{d t}-\gamma \cdot P \frac{d V}{d t}
$$

\section{MODEL VALIDATION}

The model is designed for use on a fuel-flexible engine with VVT and it is crucial that the model captures the combustion phasing over the operating range of such an engine. Experimentation to validate the model was conducted on a Renault F4RT 2.1L engine with VVT on the intake valves. The engine is port-fuel injected and turbocharged. The specifications for this engine are given in Table III.

TABLE III

ENGINE SPECIFICATIONS.

\begin{tabular}{|c|c|}
\hline Number of cylinders & 4 \\
\hline Compression ratio & 10.55 \\
\hline Bore $(\mathrm{mm})$ & 82.7 \\
\hline Stroke $(\mathrm{mm})$ & 93 \\
\hline Connecting rod length $(\mathrm{mm})$ & 144 \\
\hline
\end{tabular}

The model was validated at over 500 operating points consisting of varying combinations of speed, intake manifold pressure, valve overlap, spark ignition timing, and ethanol blend fraction. In this study, valve overlap was accomplished by altering the intake timing as shown in Figure 2. The fuels considered in the study were E0 (gasoline), E5 (5\% ethanol/ 95\% gasoline), E40 (40\% ethanol/ 60\% gasoline), and E85 (85\% ethanol/ 15\% gasoline). Engine speed, intake manifold pressure, valve overlap, spark ignition timing (SIT) were varied over the ranges shown in Table IV.

\section{TABLE IV}

RANGE OF VARIATION FOR EXPERIMENTAL CONDITIONS.

\begin{tabular}{|c|c|c|}
\hline Variable & Minimum & Maximum \\
\hline \hline Engine Speed (rpm) & 750 & 5500 \\
\hline Intake Manifold Pressure (bar) & 0.4 & 2.2 \\
\hline Valve Overlap (CA deg) & -16 & 24 \\
\hline SIT (dBTDC) & -12 & 61 \\
\hline
\end{tabular}

As shown in Figure 5, the operating points at which the model was validated cover a variety of speed/load conditions with all 4 fuel blends. These inputs affect the gas exchange and compression processes. Engine speed directly affects the amount of turbulence in-cylinder (Equation 26). The intake and exhaust temperatures and pressures will affect the mass of fresh (Equation 1) and burned gases (Equations 2 and 5). Higher intake pressures are indicative of higher load conditions (which require higher air and fuel flows). Spark timing is also significantly varied and impacts the inputs to the flame propagation model. Valve overlap also directly affects the mass of burned gases. As the burned gas fraction increases, flame speeds are slowed and earlier spark timing is required to maintain the same CA50. The equivalence ratio for a majority of these points is controlled to be 1 indicating stoichiometric combustion as expected for a spark ignition engine; however, at some high loads when operating with gasoline (E0) it becomes necessary to run rich of stoichiometric in order to lower exhaust temperatures and avoid knock [9], [12].

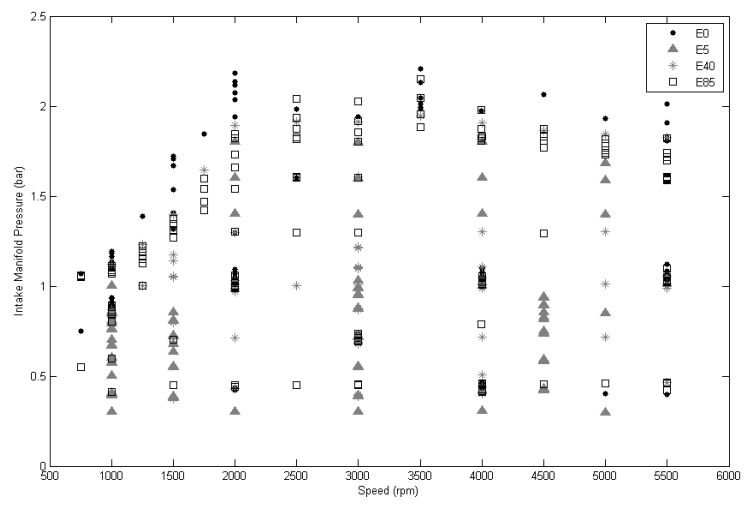

Fig. 5. Region over which model was validated.

Since this model is designed to be used for control of CA50, it is crucial that the model accurately predict CA50 for a wide variety of conditions. The accuracy of the model is demonstrated in Figure 6 which shows that the model 
accurately captures the time from spark ignition until half the fuel is burned at all the points considered (shown in Figure 5. Note that in Figure 6 the red lines represent $\pm 10 \%$ of the experimental values.

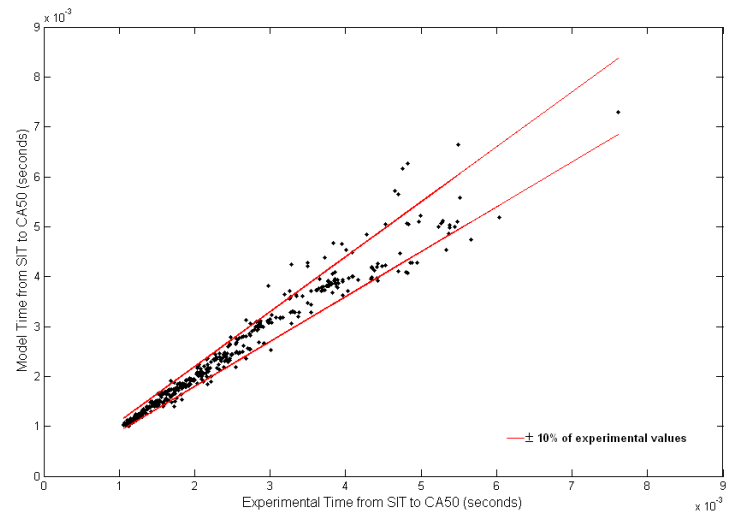

Fig. 6. Comparison between experimental value and model prediction for time between spark ignition timing and CA50 at over 500 points.

In order to further investigate the validity of the model, the model accuracy will be considered separately for E0 and E85. While results for E5 and E40 also demonstrated the accuracy of the model, these results are not shown here. Figure 7 demonstrates model prediction for E0 (gasoline). The overall trends are captured well and absolute values are also captured for most cases. Note that here the experimental values for CA50 from each of the 4 cylinders are shown.

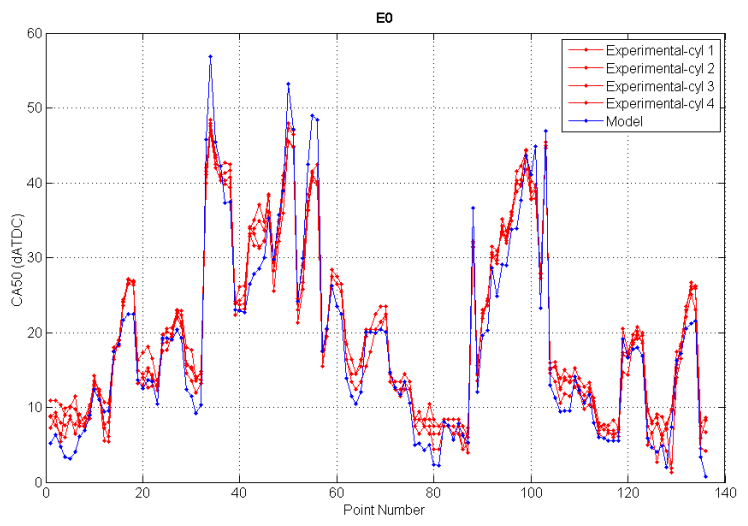

Fig. 7. Model prediction of CA50 with E0.

Figure 8 demonstrate the accuracy of the model predictions for CA50 at a variety of conditions with E85.

As demonstrated in Figure 6, for a majority of the conditions considered, the model is quite accurate for all 4 fuel blends. While more complex models may be able to capture combustion phasing with higher accuracy, such models would likely require too much computation time to be used in an actual control method.

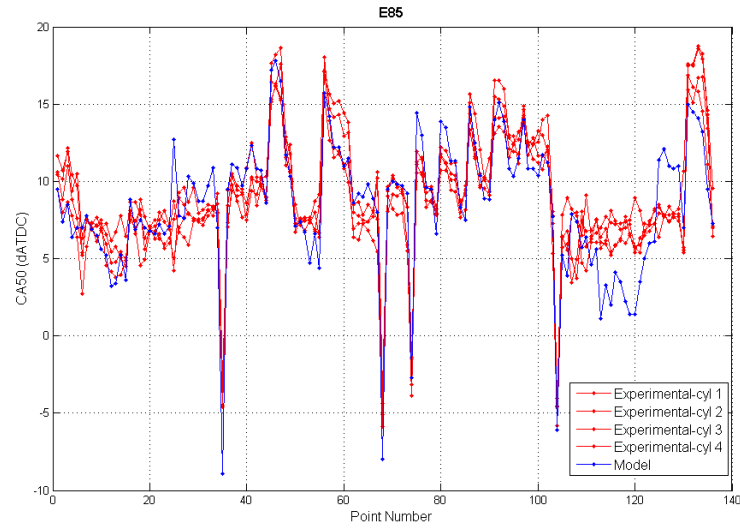

Fig. 8. Model prediction of CA50 with E85.

\section{COnClusions And Future Work}

In this work, a physically-based, generalizable combustion phasing model for fuel-flexible SI engines with VVT has been developed and demonstrated to accurately capture changes in CA50 due to variation in thermodynamic conditions, valve overlap, spark advance, and ethanol blend fraction at over 500 points across the engine operating range of a 4-cylinder fuel flexible SI engine utilizing VVT. The model captures the rate of fuel burn from SIT to CA50 within $10 \%$ of the actual experimental values at a majority (over 90\%) of these points. Furthermore, its computational simplicity and the fact that it uses only available engine sensor measurements make in extremely valuable for efforts to control combustion phasing.

In current control methods, static look-up tables are used extensively for control of ignition and while such tables provide acceptable control in steady state for their intended fuel, performance is lost during transients and when other alternative fuels are utilized. Since the model detailed in this paper can predict CA50 on a cycle-to-cycle basis for multiple fuels, it can be used in future work for feedback control or in a feedforward predictive manner to improve control during transients and when operating with alternative fuels.

\section{ACKNOWLEDGMEnTS}

This material is based upon work supported by the National Science Foundation Graduate Research Fellowship under Grant No. 103049 - Award No. 0833366. Special thanks to IFP Energies Nouvelles for providing experimental support on this project. The authors also wish to thank Lyle Kocher, Gayatri Adi, Thomas Leroy, and Thomas Coppin for their advice and contributions to this work.

\section{REFERENCES}

[1] K. Ahn, A. Stefanopoulou, and M. Jankovic, "Estimation of ethanol content in flex-fuel vehicles using an exhaust gas oxygen sensor: Model, tuning, and sensitivity," 2008 Proceedings of the ASME Dynamic Systems and Control Conference, pp. 1309-1316, 2008. 
[2] - "Tolerant ethanol estimation in flex-fuel vehicles during maf sensor drifts," Proceedings of the ASME 2009 Dynamic Systems and Control Conference, 2009.

[3] K. Ahn, A. Stefanopoulou, L. Jiang, and H. Yilmaz, "Ethanol content estimation in flex fuel direct injection engines using in-cylinder pressure measurements," SAE World Congress, Tech. Rep. 2010, 2010.

[4] F. Bonatesta and P. Shayler, "Factors influencing the burn rate characteristics of a spark ignition engine with variable valve timing," Proceedings of the Institution of Mechanical Engineers, Part D: Journal of Automotobile Engineering, vol. 222, no. 11, pp. 2147-2158, 2008.

[5] A. Bougrine, S. Richard, and D. Veynante, "Modelling and simulation of the combustion of ethanol blended fuels in a si engine using a $0 \mathrm{~d}$ coherent flame model," SAE 2009-24-0016, 2009.

[6] H. Byraktar, "Experimental and theoretical investigation of using gasoline-ethanol blends in spark-ignition engines," Renewable Energy, vol. 30, pp. 1733-1747, 2005.

[7] P. Caton, L. Hamilton, and J. Cowart, "An experimental and modeling investigation into the comparative knock and performance characteristics of e85, gasohol[e10] and regular unleaded gasoline[87(r+m)/2]," SAE 2007-01-0473, 2007.

[8] T. Coppin, O. Grondin, N. Maamri, and L. Rambault, "Fuel estimation and air-to-fuel ratio control for flexfuel spark-ignition engines," 2010 IEEE International Conference on Control Applications, 2010.

[9] T. Coppin, O. Grondin, F. L. Solliec, L. Rambault, and N. Maamri, "Control-oriented mean-value model of a fuel-flexible turbocharged spark-ignition engine," SAE 2010-01-0937, 2010.

[10] G. Fontana, E. Galloni, R. Palmaccio, and E. Torella, "The influence of variable valve timing on the combustion process of a small sparkignited engine," SAE 2006-01-0445, 2006.

[11] Ö. Gülder, "Laminar burning velocities of methanol, ethanol, isooctane-air mixtures," Nineteenth Symposium (International) on Combustion, pp. 275-281, 1982.

[12] J. Heywood, Internal Combustion Engine Fundamentals. New York, NY USA: McGraw-Hill, 1988.

[13] H. Hiroyasu and T. Kadota, "Computer simulation for combustion and exhaust emisssions on spark-ignition engine," Fifteenth Symposium (International) on Combustion, pp. 1213-1233, 1975.

[14] H. Hong, G. Parvate-Patil, and B. Gordon, "Review and analysis of variable valve timing strategies - eight ways to approach," Proceedings of the Institution of Mechanical Engineers, Part D: Journal of Automobile Engineering, 2004.

[15] J. Ramos, Internal Combustion Engine Modeling. New York, NY USA: Hemisphere Publishing Corporation, 1989.

[16] L. Kocher, E. Koeberlein, D. V. Alstine, K. Stricker, and G. Shaver, "Physically-based volumetric efficiency model for diesel engines utilizing variable intake valve actuation," 2011 Dynamics Systems and Control Conference, 2011.

[17] F. Lafossas, O. Colin, F. L. Berr, and P. Menegassi, "Application of a new 1d combusiton model to gasoline transient engine operation," SAE 2005-01-2107, 2005.

[18] F. Le Berr, M. Miche, G. L. Solliec, F.-A. Lafossas, and G. Colin, "Modelling of a turbocharged si engine with variable camshaft timing for engine control purposes," SAE 2006-01-3264, 2006.

[19] T.-K. Lee, D. Kramer, and Z. Filipi, "High-degree-of-freedom engine modelling for control design using a crank-angle-resolved flame propagation simulation and artificial neural network surrogate models," Journal of Systems and Control Engineering, 2010.

[20] T. Leroy, "Cylinder filling control of variable-valve-actuation equipped internal combustion engines," Ph.D. dissertation, MINES Paris Tech, 2010.

[21] F. Lindström, H. Ångström, G. Kalghatgi, and C. Möller, "An emperical si combustion model using laminar burning velocity correlations," SAE 2005-01-2106, 2005

[22] M. Metghalchi and J. Keck, "Burning velocities of mixtures of air with methanol, isooctane and indolene at high pressure and temperature," Combustion and Flame, vol. 48, pp. 191-210, 1982.

[23] K. Nakama, J. Kusaka, and Y. Daisho, "Effect of ethanol on knock in spark ignition gasoline engines," SAE 2008-32-0020, 2008.

[24] K. Nakata, S. Utsumi, A. Ota, K. Kawatake, T. Kawai, and T. Tsunooka, "The effect of ethanol fuel on a spark ignition engine," SAE 2006-01-3380, 2006.

[25] N. Oliverio, A. Stefanopoulou, L. Jiang, and H. Yilmaz, "Ethanol detection in flex-fuel direct injection engines using in-cylinder pressure measurements," SAE 2009-01-0657, 2009.

[26] R. Prucka, T. Lee, Z. Filipi, and D. Assanis, "Turbulence intensity calcuation from cylinder pressure data in a high degree of freedom spark-ignition engine,' SAE 2010-01-0175, 2010.

[27] S. Richard, S. Bougrine, G. Font, F. Lafossas, and F. L. Berr, "On the reduction of a $3 \mathrm{~d}$ cfd combustion model to build a physical Od model for simulating heat release, knock and pollutants in si engines," Oil Gas Science Technology - Rev. IFP, vol. 64, no. 3, pp. 223-242, 2009.

[28] O. Scharrer, C. Heinrich, M. Heinrich, P. Gebhard, and H. Pucher, "Review and analysis of variable valve timing strategies - eight ways to approach," SAE 2004-01-0614, 2004.

[29] E. Sher and T. Bar-Kohany, "Optimization of variable valve timing for maximizing performance of an unthrottled si engine - a theoretical study," Energy, vol. 27, pp. 757-775, 2002.

[30] S. B. Shrestha and G. A. Karim, "A predictive model for gas fueled spark ignition engine applications," SAE 1999-01-3482, 1999.

[31] J. Song and M. Sunwoo, "Flame kernal formation and propagation modelling in spark ignition engines," Proceedings of the Institution of Mechanical Engineers, Part D: Journal of Automobile Engineering, 2001.

[32] I. Syed, Yeliana, A. Mukherjee, J. Naber, and D. Michalek, "Numerical investigation of laminar flame speed of gasoline-ethanol/air mixtures with varying pressure, temperature, and dilution," SAE 2010-01-0620, 2010 .

[33] F. Theunissen, "Percent ethanol estimation on sensorless multi-fuel systems: Advantages and limitations," SAE 2003-01-3562, 2003.

[34] S. Turns, An Introduction to Combustion, 2nd ed. New York, NY USA: McGraw-Hill, 2000.

\section{APPENDIX}

\section{Nomenclature.}

$\bar{A}$

$a m b$

$b$

$b g$

$\delta l$

E

$f$

$\gamma$

$h$

$m_{\text {fuel }}$

$M$

$M_{\text {fuel }}$

$M_{\text {fresh }}$

$n$

$N$

$O F$

$\phi$

$P$

$Q$

$Q_{l h v}$

$R$

res

$r_{\text {flame }}$

$\rho_{u}$

$T$

$u$

$U$

$U_{L}$

$U_{t} u r b$

V

$W$

$Y_{b g}$

$Y_{\text {fuel,u }}$ mean flame area

ambient

burned

burned gas

distance between cylinder head and piston

energy

turbulence enhancement factor

heat capacity ratio

enthalpy

mass of fuel burned

mass

injected fuel mass

fresh air mass

polytropic coefficient

engine speed

overlap factor

equivalence ratio

pressure

heat

lower heating value

universal gas constant

residual

flame radius

density in the unburned zone

temperature

unburned

internal energy

laminar flame speed

turbulent flame speed

volume

work

burned gas fraction

fuel mass fraction in unburned zone 